\title{
Socio-economic development in Guatemala through incentives to the subsistence sector
}

\author{
S. G. Manger Cats ${ }^{1}$
}

Received 15 October 1969

\section{Summary}

An important part of the agricultural production in Guatemala for internal consumption, originates from smallholdings. The total value does increase only moderately, while the rise in number of these smallholders (subfamily farmers) is more than can be satisfied by the available land resources. The result is a further subdivision of plots, which without a corresponding intensification of production automatically leads to an eroding source of income. Subfamily farms (under $7 \mathrm{ha}$ ), defined as too small to fully occupy the operator's family and to provide him with an adequate income, if worked traditionally, now number some 370,000 in Guatemala.

Apart from the difficult access to new lands, there is also a skewed distribution of production inputs and credits, and even the benefits of a good market organization are limited largely to export crops like coffee, cotton and bananas. All these conditions together fix the position of the subsistence farmer in the national setting.

Several programmes exist, however, aimed at improvement of this situation. Many successful projects show the potential for improvement. Some specific measures are presented of what is required to raise production levels of the subfamily farms. The impact of higher agricultural incomes received by an important sector of the population, the smallholders' sector of Guatemala, will have a very beneficial multiplyer effect on the rest of the economy.

\section{Introduction}

A substantial part of the Guatemalan agricultural production, classified as for 'domestic consumption' (maize, beans, wheat, potatoes, fruits, vegetables, etc.) comes from the plots of small producers. A distinction is often made between subsistence and commercial farmers, according to the percentage of the product or the degree in which it is used for farm consumption or destined for the market. However in Guatemala this point cannot be generalized since a high percentage of some smallholder products such as vegetables, fruits and wheat enter into commercial channels. The criterion followed in this paper for identifying the subsistence sector is rather the gross income of the farm (in turn largely determined by the size of the holding). Assuming that an $80 \%$ of the products for domestic consumption, plus $10 \%$ of the export products (including animal products) come from the group of small farms -

1 The author is FAO technican in Land Use and Farm Management for the Central American Economic Integration Program. The present article, however, has been written in his personal capacity and does not necessarily reflect the point of view of the Food and Agriculture Organization. 
Table 1 Gross National Product (GNP) and contribution of the agricultural sector (in millions of dollars)

\begin{tabular}{lccc}
\hline Year & $\begin{array}{c}\text { GNP } \\
\text { (in millions } \\
\text { of dollars) }\end{array}$ & \begin{tabular}{c} 
Agricultural sector \\
\cline { 3 - 4 }
\end{tabular} & (in millions \\
of dollars) & (in \% of GNP) \\
1950 & 736.4 & 239.4 & 32.5 \\
1964 & $1,279.3$ & 384.8 & 30.1 \\
\hline
\end{tabular}

Source: Banco de Guatemala, Cuentas Nacionales, 1968.

adding up to some 365,000 - we get a gross income of barely $\$ 400$ per farm, an amount which does not seem very adequate to sustain a family of five during a whole year.

After a more detailed identification of the traditional agricultural sector, the objective of this article is first to underline the slow development of this numerous group and then to indicate measures that can lead to an incorporation of this sector into the national economy.

\section{Identification of the subsistence sector}

Guatemala is one of the countries in Central America where the Gross National Product (GNP) has increased satisfactorily during the last years; an increment of $80 \%$ is observed between 1950 and 1966.1 At the same time there is a percentual decline in the agricultural contribution to the total product, though at a very low rate (Table 1 ). Apparently dependence on the agricultural sector is not of such importance in Guatemala. However Table 2 shows that the bulk of the economically active population still depends on agriculture.

In addition to this, it must be taken into account that the rural population grows at an annual rate of $2.5 \%$ (Anon., 1960) and that a high percentage of this increase is found within the group of small producers. It is clear that this situation will create problems that make it opportune to analyse this sector in more detail.

Table 2 Economically active population and average income

\begin{tabular}{|c|c|c|c|c|c|c|}
\hline \multirow[t]{3}{*}{ Year } & \multicolumn{3}{|c|}{ Economically active population } & \multicolumn{3}{|c|}{$\begin{array}{c}\text { GNP per economically active person } \\
\text { (in dollars) }\end{array}$} \\
\hline & \multirow{2}{*}{ 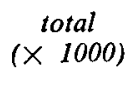 } & \multicolumn{2}{|c|}{ agricultural sector } & \multirow[t]{2}{*}{ average } & \multirow{2}{*}{$\begin{array}{l}\text { agricultural } \\
\text { sector }\end{array}$} & \multirow{2}{*}{$\begin{array}{l}\text { non-agri- } \\
\text { cultural }\end{array}$} \\
\hline & & $(\times 1000)$ & (\% of total) & & & \\
\hline 1950 & 973.6 & 664 & 68 & 756 & 360 & 1,603 \\
\hline 1964 & $1,292.0$ & 825.5 & 64 & 990 & 446 & 1,918 \\
\hline
\end{tabular}

Source: Banco de Guatemala, Cuentas Nacionales, 1968, y Censo de la Población 1964.

1 Cost of living has been stable and there was no devaluation in Guatemala.

Neth. J. agric. Sci. 18 (1970) 
Table 3 Distribution of the agricultural production units

\begin{tabular}{|c|c|c|c|c|c|}
\hline \multirow[t]{2}{*}{ Type of holding 1} & \multicolumn{2}{|c|}{1950} & \multicolumn{2}{|c|}{1964} & \multirow{2}{*}{$\begin{array}{l}\text { Estimate of farm } \\
\text { consumption as } \\
\% \text { of farm } \\
\text { production }\end{array}$} \\
\hline & number of & $\%$ of total & number of $f$ & $\%$ of total & \\
\hline $\begin{array}{l}\text { Subfamily } \\
\text { (subsistence) }\end{array}$ & 308,073 & 88.4 & 364,879 & 87.5 & 60 \\
\hline Family & 33,041 & 9.5 & 43,656 & 10.4 & 30 \\
\hline Medium multifamily & 7,057 & 2.0 & 8,420 & 2.0 & 10 \\
\hline Large multifamily & 516 & 0.1 & 389 & 0.1 & 0 \\
\hline Total for the country & 348,687 & 100.0 & 417,344 & 100.0 & \\
\hline
\end{tabular}

1 The size of the farms is, as a rule, directly related to the amount of labour employed. Therefore, the groups have been classified according to the labour employed. The type of holding varies from the subfamily type, too small to sustain a family (less than two labourers), to the multifamily type, where more than four labourers are employed the year around. Since the census does not present data relating directly to the size of the holdings with the labour force, the classification of farms is as follows: the subfamily farm has less than 7 ha, the family farm 7.1 to 45 ha, the medium multifamily farm 45.1 to $896 \mathrm{ha}$, and the large multifamily farm over 896 ha.

Source: Censo Agropecuario, 1950 and 1964.

Farm type by size

Table 3 gives the distribution of farms; on one side, the small and medium holdings in which traditional characteristics prevail, and on the other, the large (multifamily) farms, much more oriented to export products.

It can be seen from Table 3 that an overwhelming majority of the holdings are smallholders which, according to the definition, are too small to sustain a family. This situation, already described one way or another in various reports, has not changed substantially; on the contrary, the comparison of the 1950 and 1964 agricultural censuses of Guatemala indicates an increase in the number of small farmers, from 308,000 to $364,000(+18.5 \%)$, while the size of the holdings has not changed. The FAO study on land tenure in Central America (Anon., 1963) indicates a similar situation in the whole area. This means that in the Isthmus some 750,000 small producers plus some 450,000 farm workers (landless), undoubtedly summing in all to more than one million families at present, live in precarious conditions in the rural areas.

At the same time it can be observed that, the smaller the farm is, the higher is the percentage of its products used for farm consumption. While the subfamily farms use $60 \%$ of their production for their own needs, selling the remaining $40 \%$, the multifamily farms commercialize more than $90 \%$ of their produce.

\section{Production pattern}

Crop production in the farms is closely related to the above situation. Almost all subfamily and family farms grow maize both for home consumption and for sale in the local markets; likewise a large part of the other basic grains (beans, rice and wheat) is produced on these farms. The large holdings (called multifamily in Table 3 ) only produce grains to cover their own needs, since they are far more market-oriented; from them comes almost all produce for export and industrial use (coffee, cotton, bananas, meat and sugar cane), as indicated in Table 4. 
Table 4 Agricultural production according to destination in 1966

\begin{tabular}{|c|c|c|c|c|}
\hline . & $\begin{array}{c}\text { Volume } \\
\text { (1000 metric } \\
\text { tons) }\end{array}$ & $\begin{array}{c}\text { Value } \\
\text { (millions } \\
\text { of dollars) }\end{array}$ & & $\begin{array}{c}\text { Approximate percentage } \\
\text { produced in } \\
\text { (sub)family farms }\end{array}$ \\
\hline l'roducts for domestic consumption & & & 131.5 & \\
\hline Basic food crops & & 80.4 & & \\
\hline Maize & 743 & 52.2 & & 90 \\
\hline Beans & 111 & 17.4 & & 90 \\
\hline Unmilled wheat & 40 & 5.2 & & 90 \\
\hline Unmilled rice & 31 & 2.7 & & 50 \\
\hline Potatoes & 23 & 3.0 & & \\
\hline Other food products & & 51.1 & & 80 \\
\hline Fruit & & 18.2 & & \\
\hline Vegetables & 132 & 17.3 & & \\
\hline Broad beans & 6 & 0.9 & & \\
\hline Groundnuts & 0.5 & 0.1 & & \\
\hline Other & & 14.6 & & \\
\hline Products for export and industrial use & & & 176.1 & 10 \\
\hline Coffee & & 84.2 & & \\
\hline Cotton & & 45.0 & & \\
\hline Bananas & & 11.0 & & \\
\hline Sugar cane & & 18.4 & & \\
\hline Others & & 17.5 & & \\
\hline Total crop production & & & 307.6 & \\
\hline Total livestock production & & & 95.8 & 10 \\
\hline
\end{tabular}

Source: Banco de Guatemala, Cuentas Nacionales, Guatemala 1968. Values and quantities have been transferred into dollars and metric tons.

\section{Use of available resources}

As far as the land resource is concerned, the Census of Agriculture indicates that about $90 \%$ of the holdings in Guatemala occupy less than $20 \%$ of the land in farms; part of this land is located in areas that because of their ruggedness should be under forest.

Agricultural credit is mainly directed to export products; in 1966 coffee, cotton and sugar-cane received $90 \%$, and the two subsistence products, maize and beans, covering half of the cropped area, acquired together only $1.6 \%$ of the credit granted. It is also estimated that three exports products, bananas, coffee and cotton, utilize more than $80 \%$ of the fertilizers used in the country.

The same duality exists in market access. For the export products there are commercial channels, and prices do not fluctuate much in one season. However the products of the small farmer have presented many marketing problems in the past, with strong repercussions on their tendency to produce for the market; the following figures indicate the fluctuation in prices in a year in the north of the Department of Huehuetenango: maize (rom 5 to 11 dollar cents per $\mathrm{kg}$ ), potatoes ( 2 to 12 cents), barley ( 7 to 17 cents) and wheat (5 to 11 cents).

These factors and the shortage of other institutional 'inputs', such as technical assistance (CIDA, 1965, p. 116), are reflected in a low production value and, consequently, in low incomes for this group of subfamily farms as a whole. It is expected, however, that the situation concerning credit and prices of products will improve with 
(Abercrombie, 1961, p. 1-7). It is true that in some zones of smallholdings (Totonicapán in Guatemala, and the north of El Salvador), nutrition is at present deficient during certain months of the year (CIDA, 1965, p. 107-111), so that deficiencies must first be satisfied; but enlargement of the local production in order to share in national and regional markets, in this case the Central American common market, has been supported in various parts (Castillo, 1963). Some technical and institutional measures needed for the incorporation of the rural sector into the development process are presented below.

\section{Indirect measures}

The Government is already making great efforts at a national level to solve this same problem of traditional agriculture and of low income. The construction of roads and schools and other improvements in the infrastructure, and the expansion of credit systems, technical assistance and marketing are all designed to fulfill the plans and projections made precisely to help this sector. There is no doubt that these measures are all necessary to improve the situation, but in practice it can be observed that because of the lack of technicians, scarcity of funds and other inputs, the consequent breakdown of programmes, the active participation of the peasant can hardly develop. However experience shows that a $50 \%$ increase in yield is not difficult to attain. The technological achievements in combination with the personal initiative have demonstrated this in various instances, both in cases of individuals and of organized groups (CIDA, 1965, p. 166). The income increase thus obtained, both for the individual and for the group, has clearly demonstrated its effect on the attitude of the respective individuals (ter Kuile and Manger Cats, 1968). Unfortunately, these examples are always isolated cases: they do not diffuse with sufficient rapidity so as to have an impact on the economy and on the rural masses. In other words, the raising of the level of living of the agricultural sector will not be realized without a wider divulgation of technical and institutional inputs.

Another limiting factor plays an important role in this general programming. The 'illustrative' cases can multiply their commercialized production but not all the farms can increase their income, duplicating, for example, their production of basic grains (which is the only thing they could do); prices would immediately drop to levels which would make orientation to the market completely illusory (Manger Cats and Myren, 1968). In other words, higher production cannot exceed the effective demand, as export possibilities for basic foodgrains are very limited. Low elasticity of demand for agricultural products may emerge here as a limiting factor.

\section{Direct methods}

Together with the existing programmes there is the urgent need of a more vigorous approach to direct measures, capable of guiding the small producer in the development process. It is suggested that these measures generally bring about a greater participation of the people concerned. The measure proposed below should be integrally applied in order to make 'an attack in depth on the problem of poverty of $95 \%$ of the population that lives on the land' (CIAP, 1966, p. 181).

First farm prices must be stabilized at an acceptable level; this need has been under discussion for more than 15 years in Central Ámerica; perhaps the regional grain storage programme, now being implemented, will accomplish this. A minimum price received by the farmer for subsistence products is a means to arrest the increasing unbalance between plantation agriculture (for export) and the traditional production 
of basic grains. The goal here is not to maximize production itself but to maximize the employment opportunities for hundreds of thousands of rural families.

Secondly it is suggested that new and alternative crops be introduced or stimulated in subsistence zones, improving at the same time those already existing. There are already various national programmes being carried out in this field, but their strengthening with new long-range pilot projects, for example with the assistance of the United Nations, seems to be of the utmost importance. It must be taken into account in this respect that a possible project for the improvement of decidious fruit trees in the highlands of Guatemala will not be a success until after many years of instruction and organization of the indigenous producers of these regions; plantations of apples, pears and peaches have already existed in the area for many years, but the production level and the quality continue to be low notwithstanding many years of research and extension.

What is needed in relation to the promotion of many crops is the provision of technical assistance integrated with the supply of inputs and the organization of marketing, i.e. the complete organization of the crop potential. A good example on a large scale is that of the wheat improvement programme in the highlands of Guatemala through the 'Gremial Nacional de Trigueros' and the depending wheat co-operatives. These institutions provide credit for seeds and fertilizers and, besides a series of other services, guarantee the producer a remunerative price for his produce; it means an economic and social benefit for some 40,000 small producers; this is the only programme that covers such an important part of the subsistence sector. Another whose action is concentrated on smallholders is that of agricultural co-operatives in the north of the neighbouring country of El Salvador; there some hundred groups already associate some 8,000 members. Credit recovery in these co-operatives comes close to $100 \%$. Such organizations give the peasant new incentives to produce more and to try alternatives. Many co-operative and union members have already passed from the subsistence stage into that of commercialization.

Finally, also in combination with the other direct measures mentioned above, it is suggested that some sales centres of everyday necessities be established. The mere sight of many articles forms an incentive because it increases the needs of the peasant. Various co-operatives already offer this service to their members, but it could be expanded considerably.

\section{Advantages of an income increase in the subsistence sector}

It must be pointed out that the overall impact of a combination of indirect and direct measures as presented here can only be slow: in putting into effect a minimum price for grains for the hundreds of thousands of peasants, and incorporating thousands and thousands in co-operatives is a tremendous job and a very difficult one. Experience shows too that once the enthusiasm of the rural population is awoken (after six years in the poor north-central part of El Salvador, for instance), the available technicians cannot take care of the needs for assistance of so many new cooperatives.

Many economical and social benefits can be enumerated in relation to local production of kenaf, wheat, barley, rubber, paper pulp, milk products and others that also could be imported; the national production of these items sustains domestic employment and furthermore means important foreign exchange savings even if prices prevailing 
in international markets are somewhat lower. Besides these aspects, other effects could be mentioned; through the wheat improvement programme in Guatemala, for example, the use of fertilizers in other crops in the same area, such as maize, is increasing; likewise, the custom of incorporating legumes before sowing the grains is also starting to spread.

It is difficult to quantify the effect, specifically the indirect effect, that an income increase of the 400,000 small and medium producers in the country would have on the national economy. The gross income of $\$ 300,000$ for sales of wheat of a cooperative of 700 small wheat growers in one year has had a very remarkable impact in the community (ter Kuile and Manger Cats, 1968). Assuming that half of the 400,000 rural families succeed through the indicated measures in increasing their present incomes by $\$ 100$ (selling only 1.15 metric ton of grains at $\$ 87$ per ton, which is a very conservative estimate) ${ }^{1}$, the 'extra' income would reach $\$ 20$ millions. This amount generated yearly by this group will have a significant multiplier effect in the rest of the economy.

\section{Agricultural development and the common market}

Summing up, it can be said that the problem of traditional agriculture is not so much the problem of increase of food production - science and technology are capable today of realizing that. The fundamental problem lies in providing employment on their plots to a numerous and growing peasantry.

An attempt has been made in previous sections to point out that the rural sector is the largest potential outlet for the necessary expansion of the national and regional industry. On their part, the industries have their efficiences of scale in the manufacture and distribution of products, so that it is extremely important to expand the market. Castillo (1965) mentions studies which indicate that to reach this efficiency the modern industries require a market of a least 10 to 15 million buyers. Now, with $60 \%$ of the population of Central America rural and $80 \%$ of this rural population subsistence farmers, and with a poor sector within the urban population, it is easy to infer that the Central American market is at present too small for a sound development.

Only an increase in the purchasing power of $88 \%$ of the small farmers in Guatemala (indicated as subfamily in Table 3 ) and of those in neighbouring countries can open new markets for the Central American manufacture of consumer goods. Only thus will new horizons be opened for the Isthmus and for the 25 million Central Americans who will live there in 1985.

\section{References}

Abercrombie, K. C., La transición de la agricultura de subsistencia a la agricultura comercial en Africa del Sur del Sahara. FAO, Mon. Bull. agric. Econ. Statist. 10 (1961) 1-7.

Anonymous, Los recursos humanos en Centroamérica, Panamá y México en 1950-1980. UNO, 1960. Anonymous, Los problemas de tenencia de la tierra en los paises de Centro-américa. Proyecto conjunto de CEPAL-FAO-OIT, Ciudad Universitaria, Costa Rica, 1963.

1 In the case there is no market for so much maize, the sale of other products already indicated is suggested. 
Anonymous, Cuentas nacionales de Guatemala, Departamento de Estudios Económicos, Banco de Guatemala, Guatemala, 1968.

Castillo, C. M., La agricultura tradicional en una economia en desarrollo. Trimest. econ. 30 (1963). Castillo, C. M., Growth and integration in Central America. Praeger, New York, 1965, Chapter 7. CIAP, Evaluación del Plan de Desarrollo Económico y Social de Guatemala 1965/69, Unión Panamericana, Washington, D.C., 1966.

CIDA, Tenencia de la tierra y desarrollo socio-económico del sector agrícola de Guatemala. (Report by S. G. Manger Cats.) Unión Panamericana, Washington, D.C., 1965.

Kuile, C. H. ter \& Manger Cats, S., Case study on wheat growers cooperative in Guatemala. Reading, 1968.

Manger Cats, S. \& Myren, D., Producción de maíz en Centroamérica, el agricultor y el mercadeo de maíz, CIMMYT, Mexico, 1968. 